\title{
Prophages in marine bacteria: dangerous molecular time bombs or the key to survival in the seas?
}

\author{
John H Paul \\ College of Marine Science, University of South Florida, St Petersburg, FL, USA
}

\begin{abstract}
Bacteriophages are realized to be numerous and important components of oceanic food webs principally because of their lytic capabilities. The subtle changes that temperate phages impart to their hosts in the oceans are far less understood. Occurrences of lysogeny in the oceans correlate well with conditions unfavorable for rapid host growth. In coliphage $\lambda$, phage encoded repressors have been shown to modulate host metabolic gene expression and phenotype, resulting in economizing host energy expenditure. Comparison of lysogenized marine bacteria to the uninfected hosts indicated that prophage acquisition is correlated with host metabolic gene suppression. Screening 113 marine bacterial genomes for prophages yielded 64 prophage-like elements, 21 of which strongly resembled gene transfer agents (GTAs). The remaining 39 putative prophages had a relatively high incidence of transcriptional regulatory and repressor-like proteins $(\sim 2 / 40 \mathrm{~kb}$ prophage sequence) compared to lytic marine phages ( $\sim 0.25 / 40 \mathrm{~kb}$ phage sequence). Here, it has been hypothesized that marine prophages directly contribute to host survival in unfavorable environments by suppression of unneeded metabolic activities. It has been further suggested that such metabolic downshifts are the result of phage-encoded repressors and transcriptional regulators acting directly on host genes. Finally, the widespread occurrence of GTAs may be an efficient mechanism for horizontal gene transfer in the oceans.
\end{abstract}

The ISME Journal (2008) 2, 579-589; doi:10.1038/ismej.2008.35

Keywords: gene transfer agents; marine bacteria; microbial genomes; prophages; repressors

\section{Introduction}

Many phages can develop a symbiotic relationship with their hosts which is termed lysogeny (Ackermann and Dubow, 1987). This usually involves integration of the temperate phage genome (termed prophage) into one of the host's replicons. Such silent viral infections are passed to daughter cells and can be 'activated' (or induced) to cause host lysis by chemical or physical manipulations and presumably natural environmental factors that are poorly understood. Thus, prophages can be viewed as 'dangerous molecular time bombs' capable of bursting their hosts in response to environmental perturbations and spewing progeny capable of infecting other cells (Figure 1). Evidence is accumulating that the lysogenic symbiosis is a highly refined relationship resulting from the coevolution of phage and host genomes (Chen et al., 2005). However, nearly all that is known about the biology and the molecular basis of this interaction is derived

Correspondence: JH Paul, College of Marine Science, University of South Florida, 140 7th Avenue S, St Petersburg, FL 33701, USA.

E-mail: jpaul@marine.usf.edu from coliphages ( $\lambda$ and its close relatives). Much less is known of the details of lysogeny in marine bacterial isolates, and even less concerning the ecology of lysogeny in the oceans.

Here, what is known about lysogeny in the seas has been consolidated, including its occurrence, the ecology of lysogeny, some recent genomic information on putative marine prophages and the emergence of gene transfer agents (GTAs), and concluded with a unifying hypothesis of the importance of lysogeny in bacterial survival in the oceans.

\section{Occurrence of lysogeny among isolates}

The capability to detect prophages and therefore lysogeny in the ocean is only as good as our methods. Typically the occurrence of lysogeny is based upon the use of a chemical or physical treatment followed by the detection of phage particles produced. However, this procedure ignores the basic biological principal of lysogeny, the capability to establish a stable symbiosis with a host, which is far more difficult to demonstrate experimentally. Thus, defective (that is, remnant or non-infective) prophages, bacteriocins and potentially GTAs have undoubtedly been detected by this 


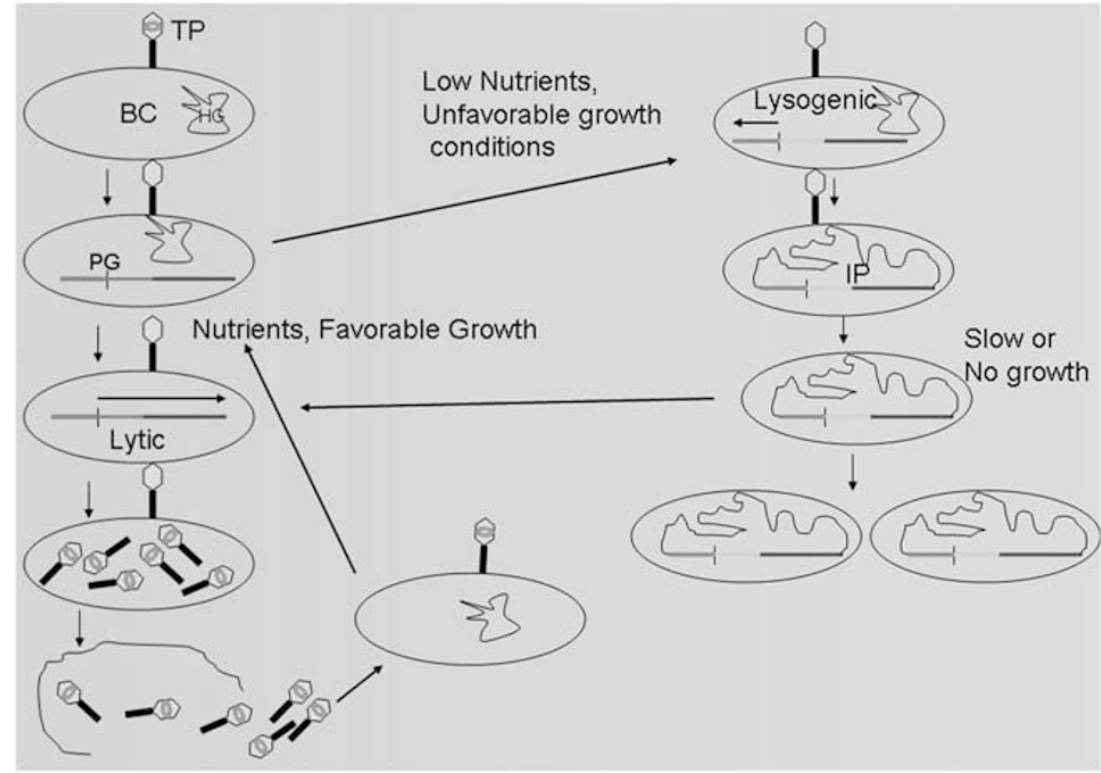

Figure 1 Schematic of the environmental control of lytic/lysogenic decision in a temperate marine phage (TP). A temperate phage attaches to a host bacterial cell (BC), injecting its phage genome (PG). If high nutrients or other environmental conditions that favor host growth exist (green background), the lytic phage genes are activated (green and blue part of the phage genome) resulting in phage production, host lysis and infection of more rapidly growing host cells. If the infection occurs during conditions unfavorable for host growth (light blue background), the lysogenic genes are activated and the phage genome integrates with the host genome (HG) to form an integrated prophage (IP). The integrated prophage can become activated to a lytic lifestyle when favorable growth conditions are restored.

procedure (Ackermann and DuBow, 1987). Additionally, not all prophages are induced by the most common chemical treatment, mitomycin C.

Lysogeny is extremely common among cultivated bacteria; $47 \%$ of 1200 diverse strains (of medical or non-marine origin) were lysogenic (Ackermann and DuBow, 1987). It has been estimated that $60-70 \%$ of the bacterial genomes sequenced to date contain prophages (Rob Edwards, Personal communication; Casjens, 2003; Casjens and Hendrix, 2005) and twothird of all sequenced $\gamma$-proteobacterial and low GC Gram-positive bacteria harbor prophages (Brussow et al., 2004). Bacterial genomes generally lacking prophages fall into two groups, the archaea and intracellular pathogens. The latter group is under tremendous pressure for genome reduction (Canchaya et al., 2004). Temperate phages of archaea have been described for Thermoproteus tenax and Sulfolobus sulfotarius (Ackermann and DuBow, 1987), but there is scant literature on other archaeal lysogens.

Marine bacterial isolates have been found to contain a high proportion (43\%) of inducible prophage-like particles (Jiang and Paul, 1994; Jiang et al., 1998). Stopar et al. (2004) found that $71 \%$ of the isolates from the Gulf of Trieste were lysogenic. The overall frequency of occurrence of inducible prophage-like particles in 130 Baltic Sea isolates was $28 \%$ (Leitet et al., 2006). Samples collected in the spring had a higher incidence of prophage than those collected in summer or fall $(\sim 35 \%)$. Collectively these results indicate that among marine bacterial isolates, roughly half contain prophages as detected by chemical induction.

Lysogeny has also been described in algae and cyanobacteria. The occurrence of lysogeny in freshwater filamentous cyanobacteria has been known for more than 35 years (Padan et al., 1972). Lysogeny has been described in marine cyanobacteria, including a filamentous strain (Ohki and Fujita, 1996) and a Synechococcus strain (Sode et al., 1994, 1997).

\section{Lysogeny in ambient marine microbial populations} The importance of lysogeny in the marine environment has been a topic of considerable debate. Early work with natural populations suggested that a relatively low proportion of marine bacteria were lysogens (Wilcox and Fuhrman, 1994). Weinbauer and Suttle $(1996,1999)$ also concluded that a small proportion (1.5-11.4\%) of the bacterial populations in the Gulf of Mexico were lysogenized. Eight of 10 eutrophic environments were found to contain inducible lysogens (bacteria whose prophage can be induced to grow lytically), whereas only 3 of 11 offshore environments contained inducible lysogens (Jiang and Paul, 1996). A series of environmentally relevant pollutants (polynuclear aromatic hydrocarbons, polychlorinated biphenyls and pesticides) could all cause prophage induction in natural populations (Jiang and Paul, 1996; Cochran and Paul, 1998). Estimates of the fraction of the bacterial population lysogenized in a seasonal study of Tampa Bay varied from 0 to approximately $100 \%$ 
(average 27.6 $\pm 24.7 \%$; Williamson et al., 2002). Further studies in Tampa Bay and British Columbia indicated that at certain times the entire population was lysogenized (Cochran and Paul, 1998; Ortmann et al., 2002). The reason for the high viral abundance in estuaries may be because of prophage induction, resulting from natural environmental factors and anthropogenic impacts.

\section{Lysogeny in natural populations of cyanobacteria}

There has been tremendous interest in the potential for lysogeny in natural populations of Synechococcus but very little data. Hewson et al. (2001) implied that a Lyngbia bloom may have been terminated by prophage induction. A seasonal study of the distribution of cyanobacterial lysogens, determined as mitomycin C-inducible viruses infective for Synechococcus WH7803, was conducted in Tampa Bay (Figure 2; McDaniel et al., 2002). As for the heterotrophic microbes, the majority of the samples induced in the winter, with one positive in August. Primary production and the incidence of lysogeny were inversely correlated, suggesting that conditions unfavorable for autotrophic growth favored lysogeny (Figure 2). This is the first definitive evidence for lysogeny among natural populations of marine Synechococcus. Because lysogeny confers immunity to infection by related viruses, it is suggested that this process accounts for the resistance to viral infection often observed in Synechococcus (Waterbury and Valois, 1993).

Wilson et al. $(1996,1998)$ suggested that phosphate levels could provide a control of the lysogenic switch in Synechococcus. When phosphate-depleted cultures of WH7803 were infected with cyanophage $\mathrm{S}-\mathrm{PM} 2$, there was an $18 \mathrm{~h}$ delay in lysis, along with an $80 \%$ decrease in burst size. These researchers concluded that S-PM2 lysogenized the Synechococcus strain under low $\mathrm{P}$ conditions. An alternate interpretation of the data is that lytic phage production was simply P-limited. It is well known that viruses salvage host nucleotides for nucleic acid synthesis, yet synthesis requires nucleotides to be energized to the NTP form, which requires energy and phosphate. In a microcosm study using waters in a Norwegian Fjord, a nitrogen enrichment experiment led to a large Synechococcus bloom $\left(5 \times 10^{5}\right.$ cells ml $\left.{ }^{-1}\right)$, which was P-limited $(\mathrm{N}: \mathrm{P}$ ratio was 75:1). Addition of $\mathrm{P}$ to the microcosm resulted in bloom collapse concomitant with a dramatic increase in phage production (Wilson et al., 1998). These workers suggested that $\mathrm{P}$ concentrations controlled the shift from lysogeny to lytic existence, although P-limitation of lytic phage production could also account for these findings. A study of the potential effect of phosphate on prophage induction in natural heterotrophic bacterial populations of the Gulf of Mexico indicated that phosphate additions stimulated lytic phage production, but had no effect on prophage induction (Williamson and Paul, 2004). In this same environment, phosphate amendment actually caused a decrease in lytic phage production in natural populations of marine Synechococcus, without stimulating mitC-induced prophage production (McDaniel and Paul, 2005).

Hewson and co-workers studied the potential for virulent phage attack of natural populations and cultures of the nitrogen-fixing pelagic cyanobacterium Trichodesmium spp. While incubating

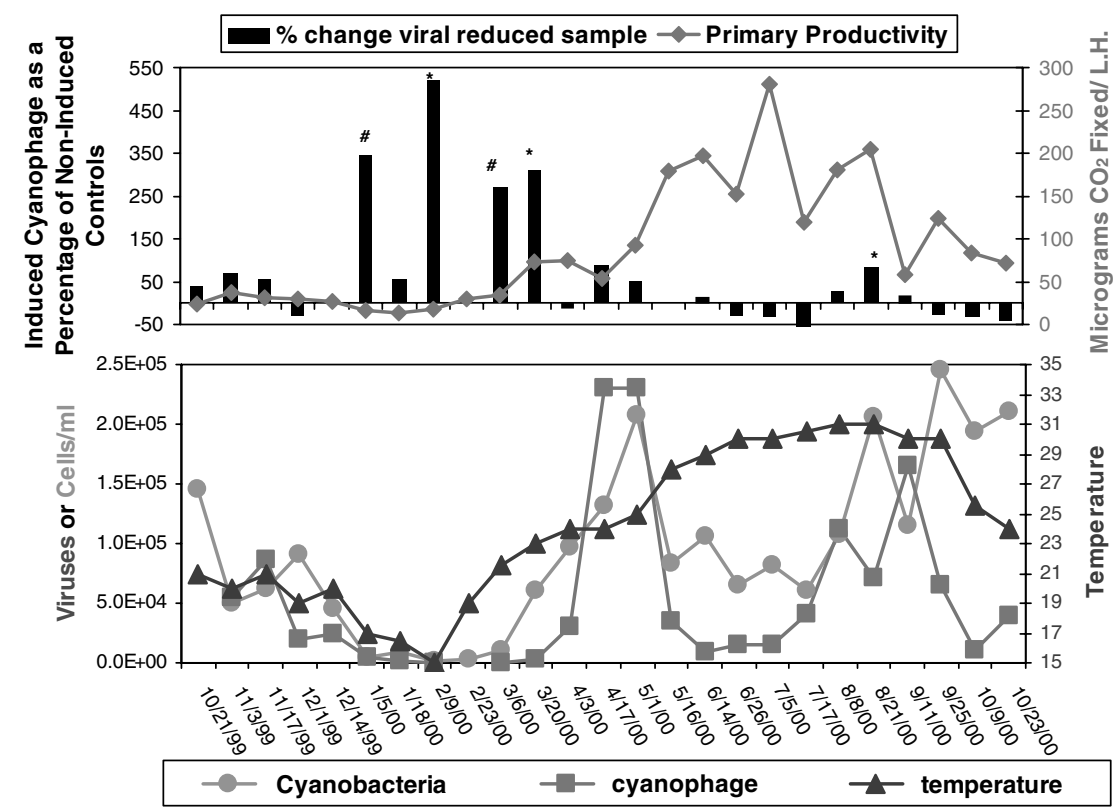

Figure 2 Level of prophage induction of Synechococcus populations (closed bar) compared to primary productivity (green diamonds), Synechococcus abundance (pink circles), cyanophage counts (brown $\square$ ) and temperature (blue $\triangle$ ). Results are expressed as percentage change in treatment compared to control ${ }^{*}$ and ${ }^{*}$ indicate statistical significance at the 95 and $90 \%$ confidence interval, respectively. 
Trichodesmium colonies in containers, these workers noted the spontaneous induction of virus-like particles and trichome lysis, believed to be the result of prophage induction. Cultivated Trichodesmium trichomes also showed production of phage when incubated with mitC (Ohki, 1999; Hewson et al., 2004).

An explanation of the variation in occurrence of lysogeny in the environment comes from the combined work of Weinbauer et al. (2003), McDaniel et al. (2002, 2006) and Williamson et al. (2002). The seasonal distribution of lysogens in Tampa Bay inversely reflected temperature, host abundance and bacterial and primary production (McDaniel et al., 2002; Williamson et al., 2002). The greatest occurrence of lysogeny was in the winter months, when bacterial and primary production was lowest. Similar observations have been made for Antarctic oligotrophic lakes, where lysogeny was detected during Austral winter and early spring samplings (Laybourn-Parry et al., 2007; Säwström et al., 2007). Lysogeny was not observed in the highly productive waters of the Mississippi River plume, whereas surface and subsurface oligotrophic waters of the Gulf of Mexico contained lysogens (McDaniel et al., 2006). Finally, analysis of Baltic and Mediterranean Sea bacterial populations indicated that subsurface populations had a higher incidence of lysogeny, including anoxic waters (Weinbauer et al., 2003). An inverse log relationship was observed between lytic infection (frequency of visibly infected cells; FVIC) and lysogeny. These results indicate that lysogeny is favored in waters of low host abundance and productivity, as a survival strategy for viruses during episodes of low energy sources or unfavorable conditions in general (Figure 1).

\section{Why be temperate?}

The advantages of lysogeny from the perspective of a phage are obvious, most notably the capability to survive times of low host abundance. This includes protection from proteolytic digestion, grazing to some degree and UV inactivation. Yet the advantages to the host are probably more subtle-the possession of extra DNA must have a metabolic cost (hence the tendency to lose non-essential plasmids through segregation). Indeed, a prophage is also a dangerous molecular time bomb that often results in the lysis of at least some of the hosts, and under certain environmental conditions, perhaps the entire host population.

Although concept that prophages enhance host fitness has been known for some time, (Edlin et al., 1975) yet how this occurs is only now being understood by a combination of physiological analyses coupled with whole genome expression array analyses. Prophage genes that promote host fitness are termed fitness factors (Brussow et al., 2004) and provide five mechanisms for accomplishing this: (1) prophages serve as anchor points for gene rearrangements, often functioning as transposons, (2) prophages can interrupt genes through insertion, producing metabolic losses through silencing non-essential gene functions, (3) prophages usually confer homoimmunity to related phage infections (resistance to superinfection), (4) lysis of closely related nearby strains ('kill the relatives') and (5) introduction of new fitness factors by conversion or transduction Jiang and Paul (1998). A sixth mechanism has been proposed here; the silencing of host genes by phage repressors.

Fitness factors are genes not essential for the phage life cycle, and are termed lysogenic conversion factors or morons (for more DNA, or genes that encode functions beyond that needed to complete the lytic infection cycle; Brussow et al., 2004). No greater attention has been given to any lysogenic conversion factors than those of pathogenic bacteria, sometimes referred to as virulence factors. Pathogenicity islands, or blocks of foreign genes encoding virulence factors have often turned out to be prophages. Well known prophage-encoded virulence factors include the cholera toxin genes of Vibrio cholera (Waldor and Mekalanos, 1996), virulence genes of Staphylococcus aureus (Sumby and Waldor, 2003), scarlet fever genes of Sterptococcus pyogenes, shiga toxin genes (Tyler et al., 2004) and many more. In fact, nearly all pathogenic bacteria contain at least one prophage (and many several), whereas pathogens whose genomes lack prophages may be the result of the strain selected for genomic sequencing (Brussow et al., 2004). Diseases of marine organisms have been shown to be the result of prophage conversion as well (Oakey et al., 2002; Munro et al., 2003).

Prophages as modulators of phenotypic diversity Prophage infection can dramatically alter the host phenotype to the point that the organism's role in the ecosystem may be changed. Although the role of the expression of prophage genes (morons) in the process of lysogenic conversion is coming to light, the way that temperate phages affect host gene expression is largely unknown. For example, phage Vibrio harveyi myovirus-like (VHML) infection of five $V$. harveyi strains resulted in altered phenotypes as determined by substrate utilization (Vidgen et al., 2006). Upon prophage infection, one $V$. harveyi was so altered phenotypically as to be profiled as a $V$. campbelli (Vidgen et al., 2006). A major observation was that there was a general suppression of substrate utilization in the prophage-infected hosts compared to their uninfected counterparts. Because different strains had differing reductions in the types of substrates utilized, it was proposed that VHML may have chromosomally integrated into different sites in different strains (Vidgen et al., 2006). However, based upon the structure of the VHML phage genome, it is doubtful that it chromosomally integrates at all in any of its hosts, but rather 


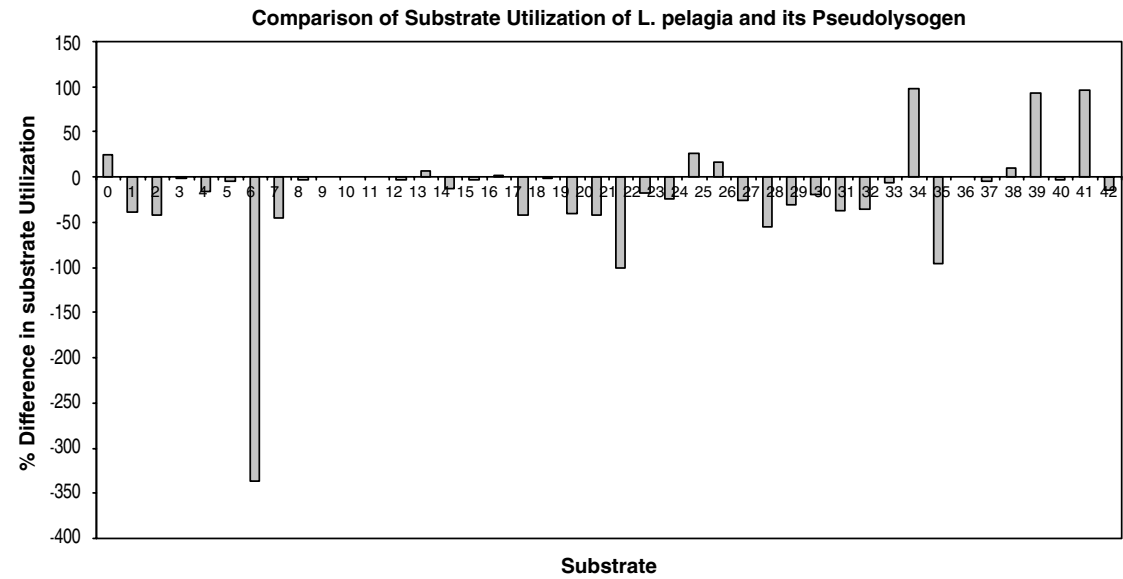

Figure 3 Relative substrate utilization between Listonella pelagia and its pseudolysogen. Values are expressed as percentage difference in substrate utilization, and are calculated as $\left(\left(\mathrm{Gr}_{\mathrm{PSEUD}}-\mathrm{Gr}_{\mathrm{LP}}\right) / \mathrm{Gr}_{\mathrm{PSEUD}}\right) \times 100$ where $\mathrm{Gr}_{\mathrm{PSEUD}}$ is the growth of the pseudolysogen and $\mathrm{Gr}_{\mathrm{LP}}$ is the growth of the uninfected L. pelagia. Substrate identity appears in Table 1 (supplement; Long, 2006).

exists as a linear plasmid as for coliphage N15 (see below).

We performed Biolog substrate utilization analysis for uninfected Listonella pelagia and its pseudolysogen infected with $\phi$ HSIC (Figure 3; Long, 2006). Pseudolysogeny is the process by which cells grow to a high cell density while producing a high titer of phages, often resulting in sigmoid growth kinetics (Ackermann and DuBow, 1987).

Positive values in Figure 3 indicate that the pseudolysogen grew better than the uninfected strain on the particular substrate, whereas negative values indicate less growth or lack of substrate utilization by the infected strain. These results indicate that prophage maintenance resulted principally in a reduction in substrate utilization capability.

How could suppression of metabolic capabilities be an advantage to a lysogen? A seminal paper on the improved fitness through phage regulation of host genes found that $\lambda$ infection resulted in the complete suppression of the host $p c k A$ gene, which encodes phosphoenolpyruvate carboxykinase, a gene critical for gluconeogenesis (Chen et al., 2005). It was found that the $\lambda$ cI repressor, which shuts down lytic phage gene expression, also bound to the operator of the $p c k A$ gene. There were at least seven potential $\mathrm{CI}$ binding sites in the -10 to -35 RNA polymerase-binding site of the operator of the pckA gene. Additionally, there were distinct cI homolog binding sites for four other temperate coliphages in this operator site. These findings argue strongly for selective pressure to acquire cIbinding sites in the operators of certain host genes, and reinforces the concept of coevolution of the phage and host in lysogeny. Chen et al. (2005) argue that the increase in fitness coming from the shutdown of the pckA gene is derived from the slower growth in a glucose-free environment, thereby providing survival in an unfavorable environment. CI repressor-like open reading frames (ORFs) have been found in marine prophage genomes (see below), including VHML (Oakey et al., 2002; Scott et al., 2006). Perhaps lysogenic repressors serve to 'throttle down' marine bacterial metabolism, conserving energy by shutting down unnecessary metabolic pathways and ensuring survival under unfavorable conditions.

\section{Marine prophage genomics}

Detection of prophages in marine bacterial genomes One hundred thirteen marine bacterial genomes were investigated for the presence of prophages based upon existing annotation (Supplementary Table 2). Proteincoding features were scanned for the term 'phage'. When a phage term was encountered, the surrounding genes were examined for other known phage genes. When clusters of phage genes were found (cluster defined as at least 3 phage genes in a 10 consecutive ORF window), the prophage-like fragment was imported into KODON (Applied Maths, Inc., Austin, TX, USA) for further analysis (checking annotation and graphical representation of prophages). Although the current annotation was generally maintained, certain ORFs were re-analysed using BLASTP and the annotation updated.

A screening of 113 marine bacterial genomes resulted in detection of 64 prophage-like elements based on our criteria (Supplementary Table 3 and Figure 1). Because of polylysogeny (a lysogen containing more than one prophage), the prophage-like elements found were spread amongst 49 bacterial strains, for an incidence of $43 \%$. Of the 64, 21 (33\%) were GTA-like elements with an average size of approximately $15 \mathrm{~kb}$ (Table 1). These were found almost exclusively in marine $\alpha$-proteobacteria, the exceptions being the $\gamma$-proteobacteria Photobacterium profundum and Geobacillus kaustophilus (Table 1). In the 1970s Barry Marrs and co-workers described 
Table 1 GTA-like elements in marine bacterial genomes

\begin{tabular}{|c|c|c|c|}
\hline Strain & Accession no. & GTA $(b p)$ & Other prophages \\
\hline Aurantimonas sp. SI85-9A1 & NZ_AAPJ00000000 & 14997 & \\
\hline Erythrobacter sp. NAP1 & NZ_AAMW00000000 & 13519 & \\
\hline Erythrobacter litoralis HTCC2594 & NC_007722 & 15643 & \\
\hline Loktanella vestfoldensis SKA53 & NZ_AAMS00000000 & 14202 & \\
\hline Maricaulis maris MCS10 & NC_008347 & 16193 & \\
\hline Nitrobacter sp. Nb-311A & NZ_AAMY00000000 & 18669 & Yes \\
\hline Oceanicaulis alexandrii HTCC2633 & NZ_AAMQ00000000 & 18172 & \\
\hline Oceanicola granulosus HTCC2516 & NZ_AAOT00000000 & 10681 & \\
\hline Photobacterium profundum 3TCK & NZ_AAPH00000000 & 11590 & \\
\hline Rhodobacterales bacterium HTCC2150 & NZ_AAXZ00000000 & 14569 & \\
\hline Rhodobacterales bacterium HTCC2654 & NZ_AAMT00000000 & 16708 & Yes \\
\hline Roseobacter CCS2 & NZ_AAYB00000000 & 14109 & \\
\hline Roseobacter denitrificans Och114 & NC_008209 & 13783 & \\
\hline Roseobacter MED 193 & NZ_AANB00000000 & 14668 & Yes \\
\hline Roseovarius nubinhibens ISM & NZ_AALY00000000 & 13917 & \\
\hline Roseovarius sp. 217 & NZ_AAMV00000000 & 17038 & \\
\hline Roseovarius sp. HTCC2601 & NZ_AATQ00000000 & 15873 & Yes \\
\hline Sagittula stellata E-37 & NZ_AAYA00000000 & 14778 & \\
\hline Silicibacter pomeroyi DSS-3 & NC_003911 & 15208 & \\
\hline Silicibacter TMS1040 Prophage 3 & NC_008044 & 16000 & \\
\hline Sulfitobacter sp. NAS-14.1 & NZ_AALZ00000000 & 14257 & Yes \\
\hline
\end{tabular}

Abbreviation: GTA, gene transfer agent.

defective phage-like particles in Rhodobacter capsulata that packaged host DNA with high efficiency catalyzing effective gene transfer and named these GTAs (Marrs, 1974). GTAs are virtually little genetic escape pods that can ensure gene survival in dying host cells. They encode for the process of 'constitutive transduction', which is one of the few procaryotic gene transfer mechanisms to be heritable and chromosomally encoded (Lang and Beatty, 2001). Although these observations were viewed as highly novel at the time, little research followed until two independent findings came to light-the report of a GTA-like sequence in the genome of Silicibacter TMS1040 (Chen et al., 2006) and the widespread occurrence of GTAs in the genome sequences of $\alpha$-proteobacteria (Lang and Beatty, 2007).

\section{Genomic organization of GTAs}

Gene transfer agents are usually smaller than prophages (13-16 kb) and have a distinctive genomic organization, normally arranged in 15 ORFs (Figure 4). The first ORF is a small one that is often missing, followed by the terminase large subunit gene. In many phages, the terminase small subunit gene precedes the large subunit, and these two genes work in unison to package the phage DNA in the capsid. Usually the small subunit possesses DNA recognition specificity and the large subunit possesses nucleolytic and ATPase activities (Lin et al., 1999). In GTAs this process has been altered to digest and package the host DNA.

It is hypothesized that the lack of a small terminase subunit is responsible for this aberrant packaging as GTAs have lost the DNA specificity function. ORFs $3-5$ are the portal, prohead protease

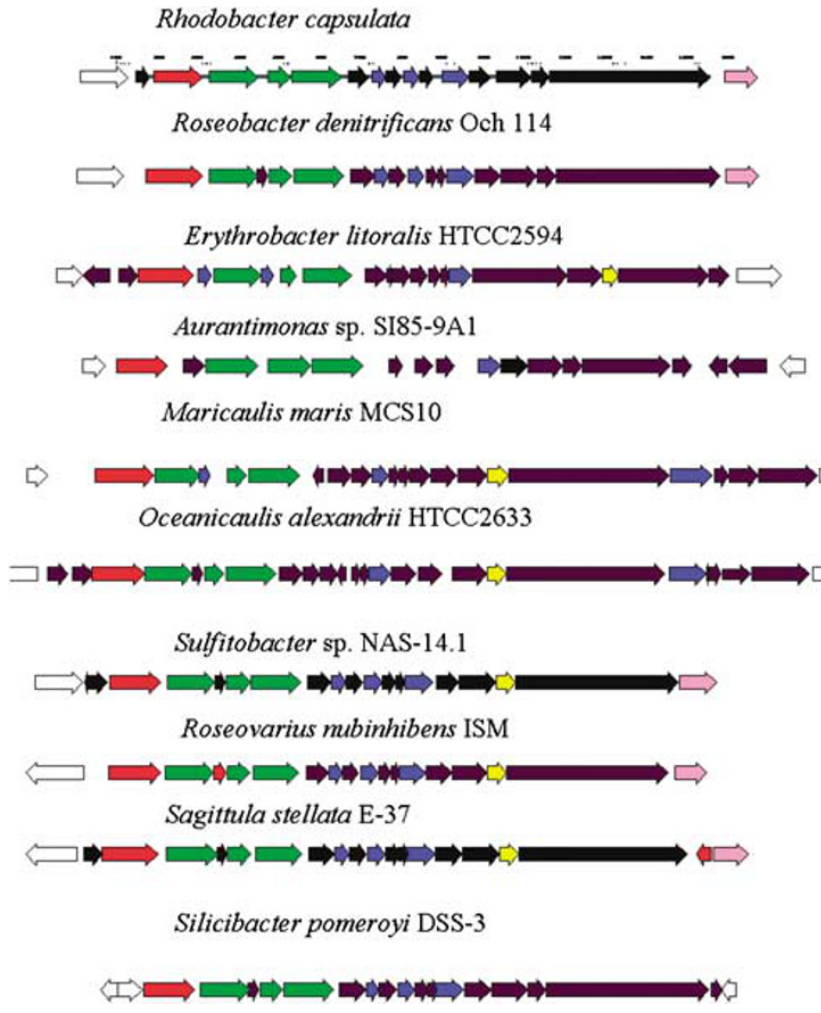

Figure 4 Genomic organization of gene transfer agents (GTAs) detected in nine marine bacterial genomes. Red-terminase large subunit; Green-portal, capsid protease and major capsid proteins; Blue-tail associated; Black, unknown or conserved hypothetical; yellow-lytic enzyme; Pink, serine O-acetyl transferase (host); white-host.

and major capsid proteins. These are usually similar to coliphage HK97. In ORFs 6-11 there are usually some tail genes, including a head to tail adapter 
protein, a major tail protein and sometimes a tail tape measure protein (these appear as blue arrows in Figure 4). Absent from the prototypical R. caspsulata GTA, but present in many marine GTAs is a cell wall hydrolase (usually ORF 14, a yellow arrow in Figure 4). A diagnostic ORF for GTAs is the large ORF 15, which is sometimes annotated as a 'host specificity' protein, although no clear function has been assigned (Lang and Beatty, 2007). Interestingly, the first host protein following the GTA is often a serine $O$ - acetyltransferase, suggesting that GTAs themselves are vertically transmitted, and are not inserting themselves in random locations as integrating prophages often do. The phylogeny of prophages seldom correlates with the phylogeny of the host, whereas the $\alpha$-proteobacteria contain a very evolutionarily conserved GTA organization (Lang and Beatty, 2007).

We have searched marine microbial metagenomes in the CAMERA database for the conserved GTA terminase using BLASTX and found 249 good hits. To determine the relative abundance of GTAs in the cells from which the metagenomes were derived, we sought to establish the ratio of the GTAs to the total number of genomes in each metagenome. Adapting the same strategy that Moran and colleagues (Howard et al., 2006) used to estimate the total genome copies in each metagenome based upon occurrence of the single copy recA homologs, GTAs were present in approximately $2.9 \%$ of the total bacterial genomes.

\section{Prophage genomic organization in marine bacteria}

A diversity of genomic organization exists for the non-GTA-like prophage elements found in marine bacterial genomes. These have been categorized based on similarities to non-marine prophage genomes in Supplementary Table 3. Our type A prophages have a Sfi11-like organization (Canchaya et al., 2004) containing a lysogeny module (coliphage $\lambda$-like integrase, and at least one phage repressor) followed by replicative genes that include a terminase, portal, capsid and tail genes (exemplified by prophages detected in Thiomicrospira crunogena and V. alginolyticus 12G01; Figure 5). These phages are $37-41 \mathrm{~kb}$ in length, and have genomic organizations shared by other cultivated phages.

Our type B prophages are similar to the type A in that they contain a recognizable integrase and are 31-49.5 kb in length but lack a discernable phage repressor protein (Supplementary Table 3). Although there is no consistent order in genomic organization among this group, five of the seven phages contain some types of DNA methylase.

The largest group of prophages are the type C, which range in size from 12 to $29 \mathrm{~kb}$, being shorter than many previously described temperate phages (Ackermann and DuBow, 1987; Canchaya et al.,

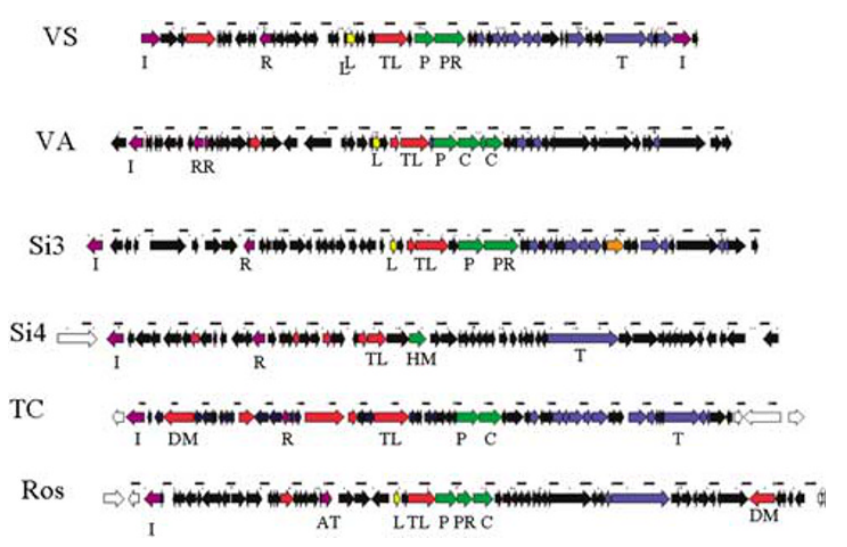

Figure 5 Genomic organization of type A prophages (VS, Vibrio splendids 12B1 prophage 1; VA, V. alginolyticus 12G01; Si3, Silicibacter TMS1040 prophage 3; Si4, Silicibacter TMS 1040 prophage 4; TC, Thiomicrospira crunogena XCL-2; Ros., Roseobacter SK209-2-6). Open reading frame (ORF) abbreviations are as follows: I, integrase; R, repressor; TS, terminase small subunit; TL, terminase large subunit; L, lysis; P, portal protein; PR, prohead protease; AT, antiterminator; C, capsid; DM, DNA methylase; HM, head morphogenesis protein. Colors of ORF relate to function groups as described in Figure 3.

2003; Casjens, 2003). Some of these may be prophage remnants, although at least one has had the sequence determined from induced prophages (Bacillus B14905 prophage 1). Ten of the type C prophages contain integrases, and four of these possess phage repressors or antiterminators, and thus could be considered shortened versions of the type A prophage elements discussed above. Of particular interest is a prophage element in Synechococcus sp 5701, the first complete prophage-like element to be recognized in a marine Synechococcus. This element contains three putative transposases and a terminal CP4-like integrase; however, no structural genes were annotated in this prophage.

Many marine prophages do not fit the criteria established for the A, B and C-type prophage groupings given above and are listed as 'other types' in (Supplementary Table 3). Three such marine prophages contained a genomic organization reminiscent of coliphage $\mathrm{Mu}$, a prophage that lacks an integrase gene. Transposable phage $\mathrm{Mu}$ infects a wide range of Gram-negative bacteria and amplifies its genome by multiple rounds of replicative transposition (Toussaint et al., 1994). Mu-like prophages are generally not inducible by mitomycin C. Control of lysogeny is effected through the action of the Rep repressor, that is encoded by the c-gene (the first ORF in Figure 5). A prophage element found in the genome of Marinomonas MED 121 is nearly identical in length (37 598 compared to 36 717) and genomic organization to that of enterobacteriophage $\mathrm{Mu}$ (Figure 6). A prophage element found in Fulvimarina pelagi HTCC2506 contained a Mu-like element linked to at least two other prophage fragments totaling $66477 \mathrm{nt}$. This included a packaging and portal protein of unknown origin, followed by 41 


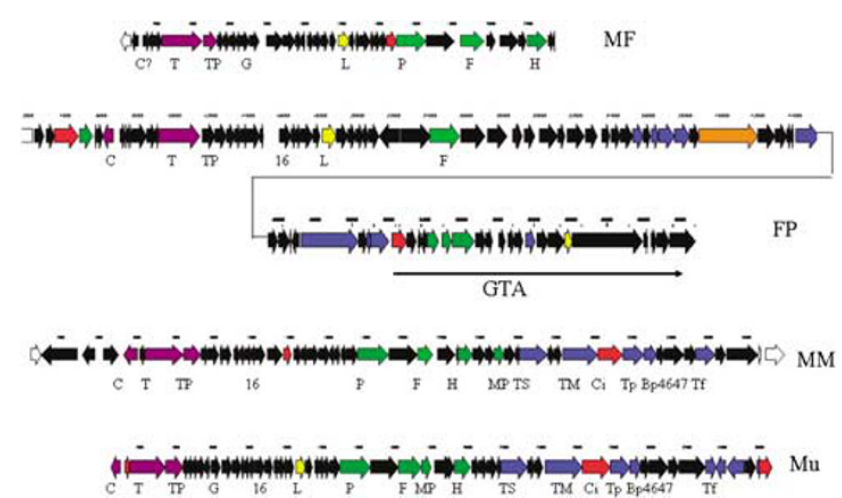

Figure $6 \mathrm{Mu}$-like prophages found in marine bacterial genomes (MF, Mariprofundus ferrooxydans pV-1; FP, Fulvimarina pelagi HTCC2506; MM, Marinomonas sp. MED121; Mu, Enterobacteriophage $\mathrm{Mu}$ ). Open reading frame (ORF) abbreviations are as follows: C, c-repressor; T, transposase; TP, transposition protein; G, gam; 16, gp16; F, virion morphogenesis F; MO, morphogenesis protein; H, major head subunit protein; TS, tail sheath; TM, tape measure; $\mathrm{Ci}$, DNA circularization protein; Tp, tail protein; Bp baseplate protein; 46,47, gp46, gp47; Tf, tail fiber protein. All other ORF abbreviations as in Figure 4, and ORF groupings by color as in Figure 3.

ORFs in the Mu-lke region, a stretch of P2-like tail proteins that included a virulence associate protein, and ended with a $21 \mathrm{ORF}$ segment highly identical to a GTA (Figure 6). It is not known if this element reflects one prophage or is a prophage and an autonomous GTA.

At least one prophage element resembled the organization and gene content of the defective prophage of Bacillus subtilis 168, PBSX. PBSX is a mitomycin C-inducible prophage-like particle that packages $13 \mathrm{~kb}$ portions of its host chromosome (Anderson and Bott, 1985), functioning like a GTA. A cluster of PBSX homologs was found in the genome of $G$. kaustophilus in a putative prophage of $33152 \mathrm{nt}$. The structure was unique in that the first 38 ORFs contained all the PBSX genes, which were followed by an entire GTA-like sequence of 14 ORFs (Supplementary Figure 1). Indeed, the GTAs may not be limited to the $\alpha$-proteobacteria; in fact it is entirely possible that they originated from defective temperate phage of the $\gamma$-proteobacteria.

One prophage-like element and two other marine phages had genomic arrangements resembling that of coliphage N15 (Figure 7). N15 is unusual in that it exists as a linear prophage with telomeric ends (Ravin and Shulga, 1970). Key components to this architecture are the protelomerase, the plasmid partitioning protein parA and a replication protein, as well as phage repressors to ensure a lysogenic lifestyle. The Halomonas aquamarina prohage HAP1 contained these genes as well as prototelomerase activity, and has been shown to exist as a linear prophage (Mobberley et al., in press). Two other marine phages, the temperate VHML (Oakey et al., 2002) of V. harveyi and VP882 of V. parahaemolyticus have nearly identical structure and are included in Figure 7.

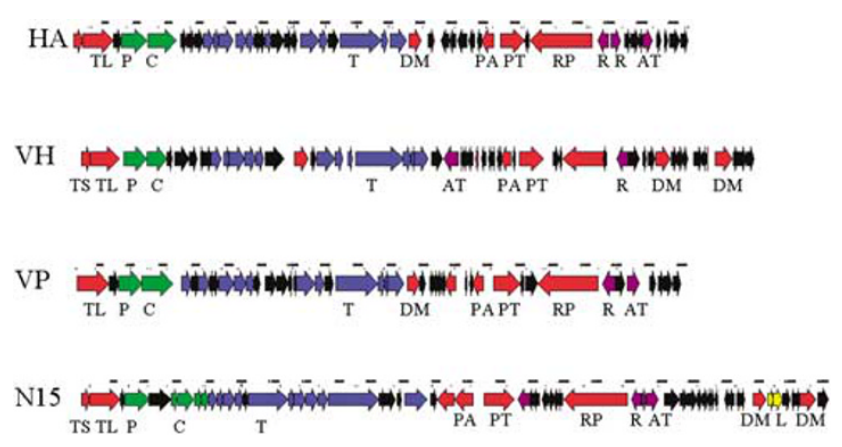

Figure 7 N15-like marine temperate phages (HA, Halomonas aquamarina prophage HAP-1; VH, Vibrio harveyi phage VHML; VP, V. parahaemolyticus phage VP882). Open reading frame (ORF) abbreviations are as follows: PA, parA protein; PT, protelomerase; $\mathrm{RP}$, replicative protein. All other ORF abbreviations as in Figure 3.

The final group of prophage-like elements do not fit any pattern of genomic organization and are simply referred to as 'disorganized prophages'. Of particular interest is the large $(>70 \mathrm{~kb})$ prophage of Silicibacter TMS1040 (prophage 1; Chen et al., 2006). This prophage has been experimentally detected by mitomycin C induction, PCR and pulsed field gel electrophoresis analysis (Chen et al., 2006). In addition to containing two integrases, there is a GTA-like element internal to the genome. This GTA-like sequence may have been the result of co-infection of Silicibacter TMS 1040 with a GTA and temperate phage that recombined in an illegitimate recombination event. Silicibacter TMS 1040 has a GTA in addition to the one detected in the large prophage element. Either this prophage picked up a GTA or this large phage is the progenitor of the current GTA.

\section{Transcriptional regulators and repressors}

We have compared the occurrence of transcriptional regulators and repressors in 20 lytic marine phages (Supplementary Table 4). Repressors and transcriptional regulators were found on the basis of existing annotation. The 42 prophage elements and 2 temperate phage genomes have a relatively high occurrence of transcriptional regulators and gene repressors (averaging 2 per genome or $2.3 / 40 \mathrm{~kb}$ sequence) compared to lytic marine phages ( 0.60 per genome or $0.23 / 40 \mathrm{~kb}$ sequence). Therefore, in addition to providing advantages conferred by conversion (including DNA methylation systems and occasional virulence proteins), marine prophages may have their greatest role in the modulation of phage and host gene expression. The example given of host cell metabolic gene repression (Chen et al., 2006) may only be a portion of the story. Certainly temperate phage genetic switches (for example, $\lambda$ ) are highly evolved to respond to metabolic and nutritive status of the host cell. It may well be that the subtleties of existence in a primarily low nutrient environment require an 
additional regulatory system encoded by the prophage that 'throttles back' metabolic activity ensuring both host and prophage survival. A higher metabolic rate might result in prophage induction under conditions that would not favor finding another host.

\section{Why are all marine bacteria not lysogenic?}

Being constantly surrounded by relatively high numbers of phages would intuitively lead to some type of phage infection (that is, lysis or lysogeny). A natural way to become resistant to infection (at least resistant to some phages) is to become lysogenized. Yet most studies of prophage occurrence in bacteria yield show that $40-60 \%$ are lysogenized (roughly half; Ackermann and DuBow, 1987; Jiang and Paul, 1994; this study). It may be that to keep lytic processes going, roughly half the bacteria need to be good hosts for lytic infection, thereby ensuring diversity through 'kill the winner'-type processes (Thingstad et al., 1997). Lytic phage infection is generally regarded to cause nearly half the bacterial mortality in the ocean, and would not occur in a totally lysogenic microbial world. An equally valid question is-where do the lysogens go when conditions favor rapid bacterial growth? Does the population shift to genotypes that are less likely to be lysogenized? Or are there massive induction events at the end of the lysogeny season resulting from environmental cues that trigger these intragenomic molecular time bombs? Very little is known concerning the environmental control of the lytic/ lysogeny switch in natural bacterial populations, partially because we lack the intensive studies of marine lysogens as have occurred for coliphage $\lambda$, and also because few studies have investigated the effects of environmental conditions or perturbations on natural populations of lysogens.

\section{Summary and conclusions}

At least half of the cultivatable marine bacteria have been shown to contain temperate phage-like particles by chemically-mediated prophage induction. The occurrence of lysogeny in natural populations at first seems to be highly variable. However, systematic study of many diverse marine environments indicate that highly productive environments are dominated by lytic phage infection, whereas oligotrophic, anoxic or seasonally stressed environments favor lysogeny. An overview of a 100 recently published marine bacterial genomes indicated that roughly $40 \%$ contained putative prophage-like elements. Surprisingly, at least one-third of the putative prophages strongly resembled GTAs. The remaining two-thirds had diverse prophage genomic organizations, resembling coliphages N15 and $\mathrm{Mu}$ and the Bacillus defective prophage element PBSX. There was a high frequency of occurrence of transcriptional regulators and repressors among the putative prophages that was not found by annotation analysis in 21 lytic marine phage genomes. Coupling these observations with the recent finding that coliphage $\lambda$ repressors can actively repress and modulate host metabolic genes, we hypothesize that marine prophages serve to repress host growth in times of resource partitioning. That is, prophages repress not only their own lytic genes but unnecessary and wasteful host metabolic process genes. Such metabolic economization enables the host (and the prophage) to survive disfavorable conditions until environmental clues alert the cell that conditions of growth have changed. Thus, prophages are not solely dangerous molecular time bombs that can bring about cell mortality, but also serve as a key to bacterial survival in the oligotrophic oceans.

\section{Acknowledgements}

This work was supported by NSF Biocomplexity Grant OCE-0221763.

\section{References}

Ackermann HW, DuBow MS. (1987). Viruses of Prokaryotes. Vol. I. General Properties of Bacteriophages. CRC Press, Inc.: Boca Raton, FL.

Anderson LM, Bott KF. (1985). DNA packaging by the Bacillus subtilis defective bacteriophage PBSX. J Virol 54: 773-780.

Brussow H, Canchaya C, Hardt W-D. (2004). Phages and the evolution of bacterial pathogens: from genomic rearrangements to lysogenic conversion. Microbiol Mol Biol Rev 68: 560-602.

Canchaya C, Fournous G, Brussow H. (2004). The impact of prophages on bacterial chromosomes. Mol Microbiol 53: 9-18.

Canchaya C, Proux C, Fournous G, Bruttin A, Brussow H. (2003). Prophage genomics. Microbiol Mol Biol Rev 67: 238-276.

Casjens S. (2003). Prophages and bacterial genomic: what have we learned so far? Mol Microbiol 49: 277-300.

Casjens S, Hendrix RW. (2005). Bacteriophages and the bacterial genome. In: Higgins PN (ed). Bacterial Chromosome. pp 39-53.

Chen F, Wang K, Stewart J, Belas R. (2006). Induction of multiple prophages from a marine bacterium: a genomic approach. Appl Environ Microbiol 72: 4995-5001.

Chen Y, Golding I, Sawai S, Guo L, Cox EC. (2005). Population fitness and the regulation of Escherichia coli genes by bacterial viruses. PLoS Biol 3: 1276-1282.

Cochran PK, Paul JH. (1998). Seasonal abundance of lysogenic bacteria in a subtropical estuary. Appl Environ Microbiol 64: 2308-2312.

Edlin G, Lin L, Bitner R. (1975). Lambda lysogens of Escherichia coli reproduce more rapidly than nonlysogens. Nature 255: 735-737.

Hewson I, O’Neil JM, Dennison WC. (2001). Viruslike particles associated with Lyngbya majuscula (Cyanophyta; Oscillatoriacea) bloom decline in Moreton Bay, Australia. Aquat Microb Ecol 25: 207-213. 
Howard EC, Henriksen JR, Buchan A, Reisch CR, Bürgmann H, Welsh R et al. (2006). Bacterial taxa that limit sulfur flux from the ocean. Science 314: 649-652.

Jiang SC, Kellogg CA, Paul JH. (1998). Characterization of marine temperate phage-host systems isolated from Mamala Bay, Oahu, Hawaii. Appl Environ Microbiol 64: 535-542.

Jiang SC, Paul JH. (1994). Seasonal and diel abundance of viruses and occurrence of lysogeny/bacteriocinogeny in the marine environment. Mar Ecol Progr Ser 104: 163-172.

Jiang SC, Paul JH. (1996). The abundance of lysogenic bacteria in marine microbial communities as determined by prophage induction. Mar Ecol Prog Ser 142: 27-38.

Jiang SC, Paul JH. (1998). Gene transfer by transduction in the marine environment. Appl Environ Microbiol 64: $2780-2787$.

Lang AS, Beatty JT. (2001). The gene transfer agent of Rhodobacter capsulatus and 'constitutive transduction' in prokaryotes. Arch Microbiol 175: 241-249.

Lang AS, Beatty JT. (2007). Importance of widespread gene transfer agent genes in $\alpha$-proteobacteria. Trends in Microbiol 15: 54-62.

Laybourn-Parry J, Marshall WA, Madan NJ. (2007). Viral dynamics and patterns of lysogeny in saline Antarctic lakes. Polar Biol 30: 351-358.

Leitet C, Riemann B, Hagstrom A. (2006). Plasmids and prophages in Baltic Sea bacterioplankton isolates. J Mar Biol Ass UK 86: 567-575.

Lin H, Rao VB, Black LW. (1999). Analysis of capsid portal protein and terminase functional domains: interaction sites required for DNA packaging in Bacteriophage T4. $J$ Mol Biol 289: 249-260.

Long AK. (2006). Control of lysogeny in marine bacteria: studies with $\varphi \mathrm{HSIC}$ and natural populations. MS Thesis, University of South Florida, Tampa.

Marrs BL. (1974). Genetic recombination in Rhodopseudomonas. Proc Natl Acad Sci USA 71: 971-973.

McDaniel L, Houchin L, Williamson S, Paul JH. (2002). Lysogeny in natural populations of marine Synechococcus. Nature 415: 496.

McDaniel L, Paul JH. (2005). Effect of nutrient addition and environmental factors on prophage induction in natural populations of marine Synechococcus species. Appl Environ Microbiol 71: 842-850.

McDaniel L, Paul JH, de la Rosa MA. (2006). Temperate and lytic cyanophages from the Gulf of Mexico. J Mar Biolog Assoc UK 86: 517-527.

Mobberley JM, Authement N, Paul JH, Segal AM. The temperate marine phage $\Phi$ HAP-1 of Halomonas aquamarina possesses a linear plasmid-like prophage genome. $J$ Virol (in press).

Munro J, Oakey J, Bromage E, Owens L. (2003). Experimental bacteriophage-mediated virulence in strains of Vibrio harveyi. Dis Aquat Org 54: 187-194.

Oakey HJ, Cullen BR, Owens L. (2002). The complete nucleotide sequence of the Vibrio harveyi bacteriophage VHML. J Appl Microbiol 93: 1089-1098.

Ohki K. (1999). A possible role of temperate phage in the regulation of Trichodesmium biomass. Bull Inst Ocean Monaco 19: 287-291.

Ohki K, Fujita Y. (1996). Occurrence of a temperate cyanophage lysogenizing the marine cyanophyte Phormidium persicinum. J Phycol 32: 365-370.

Ortmann AC, Lawrence JE, Suttle CA. (2002). Lysogeny and lytic viral production during a bloom of the cyanobacterium Synechococcus spl. Microbial Ecol 43: 225-231.

Padan E, Shilo M, Oppenheim AB. (1972). Lysogeny of the blue-green alga Plectonema boryanum by LPP2-SPI cyanophage. Virology 47: 525-526.

Ravin VK, Shulga MG. (1970). Evidence for extrachromosomal location of prophage N15. Virology 40: 800-807.

Säwström M, Anesio A, Grane'li W, Laybourn-Parry J. (2007). Seasonal viral loop dynamics in two large ultraoligotrophic Antarctic freshwater lakes. Microbial Ecol 53: 1-11.

Scott KM, Sievert SM, Abril FN, Ball LA, Barrett CJ, Blake RA et al. (2006). The genome of deep-sea vent chemolithoautotroph Thiomicrospira crunogena. PLoS Biol 4: 1-17.

Sode K, Oonari R, Oozeki M. (1997). Induction of a temperate marine cyanophage by heavy metal. $J$ Mar Biotech 5: 178-180.

Sode K, Oozeki M, Asakawa K, Burgess JG, Matsunaga T. (1994). Isolation of a marine cyanophage infecting the marine unicellular cyanobacterium, Synechococcus so NKBG 042902. J Mar Biotech 1: 189-192.

Stopar D, Cerne A, Zigman M, Poljisal-Prijatelj M, Turk V. (2004). Viral abundance and high proportion of lysogens suggest that viruses are important members of the microbial community in the Gulf of Trieste. Microb Ecol 47: 1-8.

Sumby P, Waldor MK. (2003). Transcription of the toxin genes present within the staphylococcal phage $\phi S a 3 \mathrm{~ms}$ is intimately linked with the phage's life cycle. J Bacteriol 185: 6841-6851.

Thingstad TF, Hagstrøm A, Rassoulzadegan F. (1997). Accumulation of degradable DOC in surface waters: Is it caused by a malfunctioning microbial loop? Limnol Oceanogr 42: 398-404.

Toussaint A, Gama MJ, Laachouch J, Maenhaut-Michel G, Mhammedi-Alaoui A. (1994). Regulation of bacteriophage $\mathrm{Mu}$ transposition. Genetica 93: 27-39.

Tyler JS, Mills MJ, Friedman DI. (2004). The operator and early promoter region of the Shiga toxin type 2encoding bacteriophage $933 \mathrm{~W}$ and control of toxin expression. J Bacteriol 186: 7670-7679.

Vidgen MJ, Carson M, Higgins M, Owens L. (2006). Changes to the phenotypic profile of Vibrio harveyi myovirus-like (VHML) bacteriophage. J Appl Microbiol 100: 481-487.

Waldor JK, Mekalanos JJ. (1996). Lysogenic conversion by a filamentous phage encoding cholera toxin. Science 272: $1910-1914$.

Waterbury JB, Valois FW. (1993). Resistance to cooccurring phages enables marine Synechococcus to coexist with cyanophages abundant in seawater. Appl Environ Microbiol 59: 3393-3399.

Weinbauer MG, Brettar I, Hofl. (2003). Lysogeny and virusinduced mortality of bacterioplankton in surface, deep, and anoxic marine waters. Limnol Oceanogr 48: 1457-1465.

Weinbauer MG, Suttle CA. (1996). Potential significance of lysogeny to bacteriophage production and bacterial mortality in coastal waters of the Gulf of Mexico. Appl Environ Microbiol 62: 4374-4380.

Weinbauer MG, Suttle CA. (1999). Lysogeny and prophage induction in coastal and offshore bacterial communities. Aquat Microb Ecol 18: 217-225.

Wilcox RM, Fuhrman JA. (1994). Bacterial viruses in coastal seawater: lytic rather than lysogenic production. Mar Ecol Prog Ser 114: 35-45. 
Williamson SJ, Paul JH. (2004). Nutrient stimulation of lytic phage production in bacterial populations of the Gulf of Mexico. Aquat Microb Ecol 36: 9-17.

Williamson S, McDaniel L, Houchin L, Paul JH. (2002). Seasonal variation in lysogeny as depicted by prophage induction in Tampa Bay, Florida. Appl Environ Microbiol 68: 4307-4314.
Wilson WH, Carr NG, Mann NH. (1996). The effect of phosphate status on the kinetics of cyanophage infection in the oceanic cyanobacterium Synechococcus sp. WH 7803. J Phycol 32: 506-516.

Wilson WH, Turner S, Mann NH. (1998). Population dynamics of phytoplankton and viruses in phosphatelimited mesocosm and their effect on DMSP and DMS production. Estuar Coast Shelf Sci 46: 49-59.

Supplementary Information accompanies the paper on The ISME Journal website (http://www.nature.com/ismej) 